Check for updates

Cite this: Environ. Sci.: Atmos., 2022, 2, 539

Received 3rd September 2021

Accepted 16th February 2022

DOI: $10.1039 /$ d1ea00070e

rsc.li/esatmospheres

\section{Ozone uptake by commercial brake pads and brake pad components: assessing the potential indirect air quality impacts of non-exhaust emissions $\uparrow$}

\author{
Laura C. Matchett, (D) ab Maya Abou-Ghanem, (1D b Kristyna A. R. Stix, \\ Devon T. McGrath (D) ${ }^{c}$ and Sarah A. Styler (iD *ab
}

\begin{abstract}
Non-exhaust emissions have surpassed exhaust emissions in their contribution to traffic particulate matter (PM). One major type is brake wear and, although its physical and toxicological properties have been studied, its atmospheric reactivity is unknown. In a first step toward addressing this knowledge gap, we explored the reactivity of ground brake pads (ceramic, semi-metallic, organic) and common brake pad components (phenolic resin, graphite, $\mathrm{Fe}_{2} \mathrm{O}_{3}, \mathrm{Fe}_{3} \mathrm{O}_{4}, \mathrm{Fe}$ and $\mathrm{Cu}$ powders) with ozone, an important urban pollutant. The steady-state surface area-normalized ozone uptake coefficients $\left(\gamma_{\mathrm{BET}, \mathrm{SS}}\right)$ for the brake pads were $(1-3) \times 10^{-6}$ under dark conditions and increased to $(2-5) \times 10^{-6}$ upon illumination. Interestingly, whereas $\gamma_{\mathrm{BET}, \mathrm{SS}}$ values were similar for all sample types, $\gamma_{\mathrm{BET}}$ values at shorter ozone exposure times were larger and exhibited greater sample-to-sample variability $\left(\gamma_{\text {BET,30min }}=(0.7-9) \times\right.$ $10^{-5}$ ). As all brake pad components tested were reactive toward ozone, we conclude that multiple mechanisms likely underlie the observed sample reactivity. Our $\gamma_{\text {BET }}$ values suggest that ozone loss to "real-world" brake material may be larger than to organic PM during high-traffic periods. As this loss pathway is still small compared to ozone dry deposition, we suggest that future studies of brake wearozone interactions focus on their potential to change brake wear properties (e.g., hygroscopicity, toxicity) relevant in an air quality context.
\end{abstract}

Environmental significance

A large fraction of particulate matter (PM) in cities comes from non-exhaust traffic emissions (e.g., brake and tire wear). Our ability to predict the air quality impacts of this PM class is currently limited by a lack of knowledge regarding its atmospheric reactivity. Here, we investigate the reactivity of ground commercial brake pads and brake pad components with ozone, a model gas-phase pollutant. Although all brake pads studied display a large ozone reactivity, atmospheric brake wear mass loadings are too small for this to represent a significant ozone loss pathway. However, as the oxidation of brake wear and other non-exhaust PM types could potentially lead to changes in their properties, further interdisciplinary studies of this emerging class of urban PM are warranted.

${ }^{a}$ Department of Chemistry \& Chemical Biology, McMaster University, Hamilton, L8S 4M1, Canada. E-mail: stylers@mcmaster.ca

${ }^{b}$ Department of Chemistry, University of Alberta, Edmonton, Alberta, T6G 2G2, Canada

'Department of Chemistry, Memorial University of Newfoundland, St. John's, Newfoundland and Labrador, A1C 5S7, Canada

$\uparrow$ Electronic supplementary information (ESI) available: Description of the coated-wall flow tube setup; brake pad grinding and brake pad component chemical information; tube preparation details with chemical information; experimental protocol and uptake coefficient calculations; method details and further result discussion on characterization via BET surface area analysis, ICP-MS, combustion analysis, TGA, and XRD; ozone flux calculations and discussion; representative reaction profiles (Fig. S1 and S2); TGA data (Fig. S3); brake pad part information (Table S1); masses used for coating (Table S2); characterization results (Tables S3-S7); tabulated uptake coefficients (Tables S8 and S9); diffusion correction values (Table S10); ratios of time-dependent to steady-state uptake coefficients (Table S11) (PDF); X-ray diffraction patterns for brake pad samples (PDF). See DOI: 10.1039/d1ea00070e

\section{Introduction}

Ambient particulate matter (PM) exposure is a leading global risk factor for premature death. ${ }^{1}$ In cities, traffic emissions are responsible for $\sim 25 \%$ of PM loadings. ${ }^{2}$ Although air quality regulations have precipitated dramatic decreases in PM emissions from vehicle exhaust, the same is not true for PM emissions associated with brake, tire and road surface abrasion; ${ }^{3-5}$ as a result, these non-exhaust PM sources currently contribute more than half of traffic-associated PM. ${ }^{4-7}$ In future, widespread adoption of electric vehicles has the potential to offset air quality gains associated with the move away from internal combustion engine vehicles, as their higher mass confers higher brake, tire, and road abrasion rates and correspondingly higher non-exhaust PM emissions. ${ }^{8}$

According to source apportionment studies, brake wear contributes $16-55 \%$ of non-exhaust $\mathrm{PM}_{10}$ (PM with diameter $<$ 
$10 \mu \mathrm{m})$ loadings in urban environments. ${ }^{9}$ Although its emission rates, ${ }^{\mathbf{1 0 - 1 2}}$ size distribution, ${ }^{\mathbf{1 3 - 1 5}}$ chemical composition, ${ }^{\mathbf{1 0 , 1 4 , 1 6}}$ and toxicological properties ${ }^{\mathbf{1 7 - 2 0}}$ have been studied, its atmospheric reactivity has not. Since many individual components of brake pads (e.g., metal oxides and unsaturated organic compounds) ${ }^{\mathbf{2 1}}$ are reactive with atmospheric trace gases ${ }^{22-27}$ this knowledge gap limits our ability to predict the potential impacts of brake wear-trace gas interactions on the composition of the urban troposphere and the properties of brake wear PM itself. ${ }^{22}$

Here, using ozone as a model gas-phase pollutant and ground brake pad particles as a simplified proxy for brake wear PM generated under mild braking conditions, we investigate for the first time the atmospheric reactivity of material relevant to vehicle non-exhaust PM. To understand the relationship between brake material composition and reactivity, we studied three brake pad types from two manufacturers, as well as six common components of brake pads. This study provides new insight into the potential indirect air quality impacts of nonexhaust PM emissions.

\section{Methods}

\subsection{Sample selection and characterization}

To capture the breadth of passenger vehicle brake pad compositions, which confer different benefits in terms of braking efficiencies, noise properties, and lifetimes, ${ }^{9}$ we studied three different commercial types (ceramic, semi-metallic, and organic) from two different manufacturers (NAPA and PBR, both purchased from http://www.napacanada.com; see Table $\mathrm{S} 1 \dagger$ for part numbers and compatible vehicles). For a given vehicle, the front and rear brake pads may have different compositions; ${ }^{28}$ here, we studied the reactivity of front brake pads, as they are responsible for the majority of vehicle braking power. ${ }^{9}$

We characterized samples via inductively coupled plasma mass spectrometry (ICP-MS; elemental composition, 58 elements; Fig. 2), combustion analysis (total C/total N; Fig. 2), $\mathrm{X}$-ray diffraction (XRD; crystalline phase identification; Table S5 $\dagger$ ), thermogravimetric analysis (TGA; organic/elemental $\mathrm{C}$; Fig. S3 $\uparrow$ ), and nitrogen adsorption analysis (specific Brunauer-Emmett-Teller (BET) surface area determination; Table $\mathrm{S} 3 \dagger)$; detailed procedures for each technique are presented in the ESI. $\dagger$

To better understand which materials contribute to brake pad reactivity, we investigated six common brake pad components, which we selected based on the compositional analyses described above. We chose phenolic resin, a common binder, ${ }^{21}$ and graphite, a common lubricant, ${ }^{21}$ to represent the organic and elemental carbon fractions of the samples, respectively. Iron, present in large quantities in all brake pads except the organic PBR sample (Fig. 2), can occur in different forms in brake pads; ${ }^{21}$ thus, we investigated the reactivity of Fe powder (Fe), hematite $\left(\mathrm{Fe}_{2} \mathrm{O}_{3}\right)$, and magnetite $\left(\mathrm{Fe}_{3} \mathrm{O}_{4}\right)$. Finally, as two of the PBR samples contain large amounts of $\mathrm{Cu}$ (Fig. 2), we investigated the reactivity of $\mathrm{Cu}$ powder.

\subsection{Experimental procedure}

All brake pad experiments were conducted using freshly ground samples, which were produced by grinding commercial brake pads (30 s, $3800 \mathrm{rpm}$ ) in a Wig-L-Bug grinder mixer equipped with a stainless steel vial $\left(1.3 \mathrm{~cm}\right.$ id, $2.5 \mathrm{~cm}$ length; $3.3 \mathrm{~cm}^{3}$ volume) and a single stainless steel ball pestle $(0.6 \mathrm{~cm}$ diameter). Hereafter, we use the term "brake pads" to designate this material. We used ground brake pads rather than brake wear generated from a vehicle or brake dynamometer for two reasons: first, mechanical abrasion is an important process in brake wear generation; ${ }^{9}$ second, brake dynamometers produce only small amounts of sample, are expensive and timeconsuming to run, and introduce multiple variables to the brake wear generation process (e.g., initial speed, deceleration rate), all of which would have limited the range of samples investigated here. Importantly, studies have shown that the composition of emitted brake wear PM differs from that of the parent material; we discuss the potential reactivity impacts of these compositional differences in Section 3.4. The brake pad components were used as received.

We quantified ozone uptake by our brake material sample set using an atmospheric pressure coated-wall flow tube photoreactor, which our group has previously used to investigate the photochemical reactivity of titanium-containing minerals relevant to desert dust. ${ }^{23}$ The reactor consists of a sample-coated Pyrex tube inside a water-chilled jacket and surrounded by four UV-A lamps (300-410 nm, $\lambda_{\max }: 356 \mathrm{~nm}$ ); the exposure of coatings to ozone is controlled using a movable injector. Experiments were performed under environmentally relevant conditions (295 K, 25\% relative humidity [RH]) and at an ozone mixing ratio of $\sim 50 \mathrm{ppb}$, which in Canada is the threshold that triggers "actions to prevent air quality deterioration". ${ }^{29}$ All experiments were conducted using samples dispersed in $\mathrm{a}^{\mathrm{SiO}_{2}}$ matrix; grinding reproducibility and coating uniformity were assessed using replicate experiments ( $n=3$ for brake pads; $n=$ 2 for brake pad components). Additional information regarding

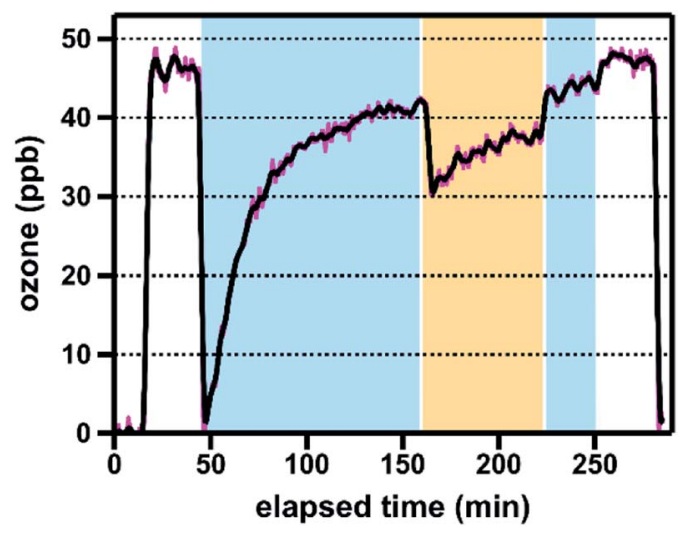

Fig. 1 Reaction profile for the uptake of ozone by semi-metallic NAPA brake pad material at $25 \% \mathrm{RH}$. The blue and yellow underlays indicate periods of exposure to ozone in the dark and the light, respectively. The black line is smoothed data ( 3 min moving average), and the pink line is the original unsmoothed data. 
the tube coating process, the photoreactor, and experimental protocols is provided in the ESI. $\dagger$

An exemplary ozone reaction profile is shown in Fig. 1; representative reaction profiles for all five brake pads and six brake pad components are shown in Fig. S1 and S2, $\dagger$ respectively. As described in the ESI, $\dagger$ we quantified the reactivity of each sample using matrix reactivity-corrected and surface areanormalized uptake coefficients $\left(\gamma_{\mathrm{BET}}\right)$, which represent the fraction of ozone-surface collisions that lead to ozone loss from the gas phase. ${ }^{22}$ To better understand the reactivity of brake material over both short and extended ozone exposure timescales, we report both time-dependent $\left(\gamma_{\mathrm{BET}, t} ; 15,30\right.$, and $60 \mathrm{~min}$ ozone exposure) and steady-state $\left(\gamma_{\mathrm{BET}, \mathrm{SS}}\right)$ uptake coefficients for all samples.

\section{Results and discussion}

\subsection{Brake pad characterization}

The brake pad elemental composition determined by ICP-MS (Fig. 2) agrees with previous literature., ${ }^{9,10,14,16}$ Despite contributions from similar components, including ceramic fibers, clays, metal powders, oxides, sulfides, and sulfates (Table S5, $\dagger$ XRD), the composition of individual brake pads varies with commercial classification. In the case of the PBR brake pads, for example, the semi-metallic is mostly composed of $\mathrm{Fe}$, whereas the ceramic contains a diverse array of elements (in particular more $\mathrm{Mg}, \mathrm{Cu}$, $\mathrm{Zn}$, and $\mathrm{Sb}$ ) and the organic has a low total metallic content (Fig. 2b). On the other hand, the NAPA samples (ceramic and semi-metallic) contain many of the same components (Tables S5 and $\mathrm{S} 6, \uparrow$ XRD and safety data sheets) and have correspondingly similar elemental compositions (Fig. 2a). In addition, as manufacturers employ their own proprietary material blends, brake pad composition can vary within the same commercial classification. For example, the ceramic and semi-metallic PBR samples contain more Fe than their NAPA counterparts (Fig. 2); this Fe is present in its elemental form in the PBR samples, but as iron oxides in the NAPA samples (Table S5 $†$ ). Additionally, the PBR samples contain more elements associated with metal powders, oxides, and/or sulfides ( $\mathrm{Cu}, \mathrm{Zn}$, and $\mathrm{Sb}$ ), whereas the NAPA samples contain more elements associated with ceramic fibers
(Al, K, Ca, and Ti). Brake pad carbon speciation also displays manufacturer variability: the NAPA samples contain more elemental carbon (e.g., graphite, carbon black), while all samples contain a similar amount of organic carbon (e.g., phenolic resin) (Fig. S3, $\uparrow$ TGA). Additional discussion of the characterization results is provided in the ESI. $\dagger$

\subsection{Steady-state ozone uptake by brake materials}

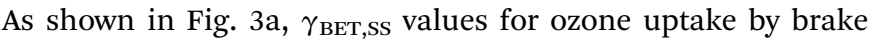
pads under dark conditions are within a factor of five, ranging from $(8.9 \pm 0.4) \times 10^{-7}$ for semi-metallic NAPA to $(3.9 \pm 0.9) \times$ $10^{-6}$ for ceramic PBR. Under illumination, ozone uptake by all samples increases, with $\gamma_{\mathrm{BET}, \mathrm{SS}}$ values ranging from $(2.0 \pm 0.5)$ $\times 10^{-6}$ for semi-metallic PBR to $(6.0 \pm 0.7) \times 10^{-6}$ for ceramic PBR.

Given the differences in brake pad composition described above, we had expected our samples to span a broader range of reactivities. Their unexpectedly similar $\gamma_{\mathrm{BET}, \mathrm{SS}}$ values likely reflect additive contributions from their respective components (Fig. 3b). For example, $\gamma_{\text {ВET,Ss }}$ values for the ceramic and semimetallic PBR samples may have a larger contribution from Fecontaining components (all with similar $\gamma_{\mathrm{BET}, \mathrm{SS}}$ values, as shown in Fig. 3b) than the NAPA samples (Fig. 2), whereas $\gamma_{\mathrm{BET}, \mathrm{SS}}$ values for the NAPA samples may have a larger contribution from graphite (Fig. S3†). Additionally, since all brake pads have a similar organic content $(\sim 14 \%$, Fig. S3 $\dagger)$, they will likely have a similar and significant contribution from the phenolic resin to $\gamma_{\mathrm{BET}, \mathrm{SS}}$.

These multiple reactivity contributions indicate that ozone uptake by brake pads likely occurs via multiple mechanisms, such as addition to double bonds (unsaturated organics), ${ }^{25,26}$ decomposition at active sites (hematite; $\alpha-\mathrm{Fe}_{2} \mathrm{O}_{3}$ ), ${ }^{24}$ reaction at unsaturated sites (graphite), ${ }^{30,31}$ and redox reactions (metals). ${ }^{32,33}$ Similarly, multiple plausible mechanisms exist for photoenhanced ozone uptake by brake pads, including energy transfer from photoexcited phenolic resin to molecular oxygen, with subsequent reaction of singlet oxygen with ozone, ${ }^{26,34}$ and reduction of ozone by photogenerated electrons produced by semiconducting iron oxides. ${ }^{27}$
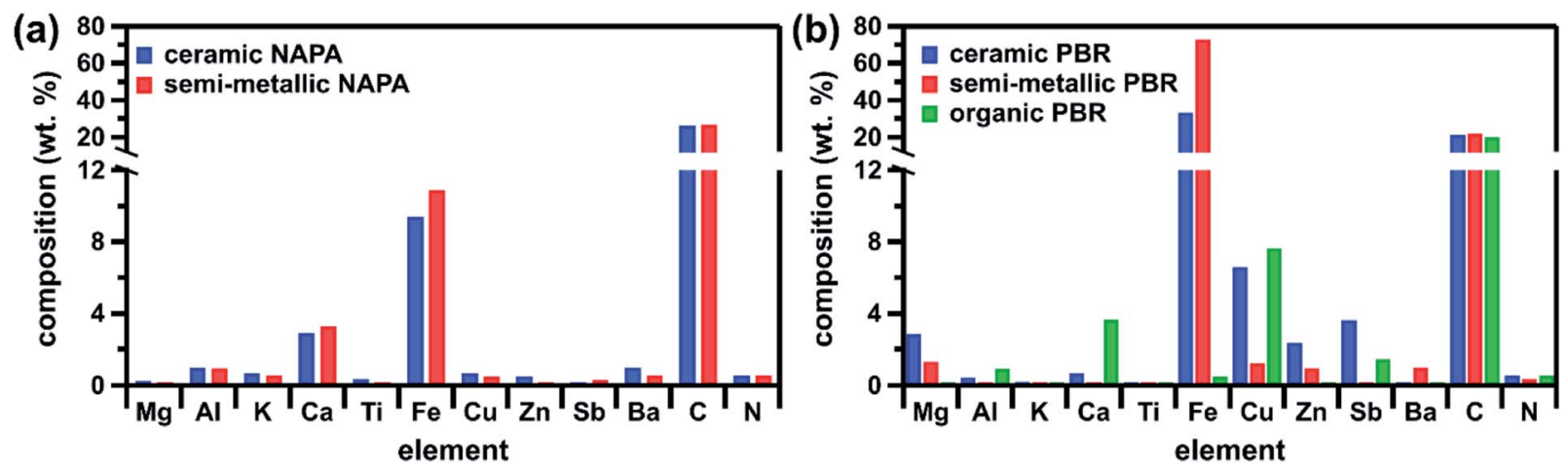

Fig. 2 Elemental composition of brake pads from (a) NAPA and (b) PBR as determined by ICP-MS and total C/total N combustion analysis. All data shown here are presented numerically in Table S4.† 

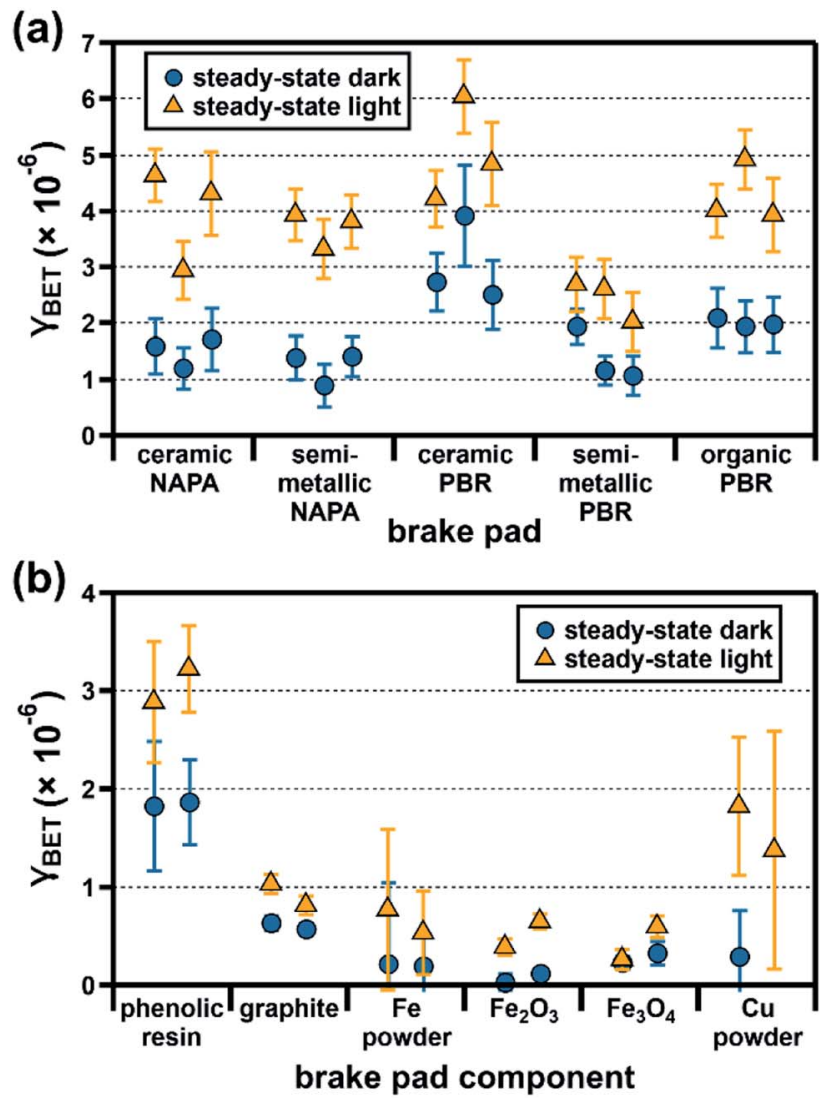

Fig. 3 Steady-state BET uptake coefficients $\left(\gamma_{\mathrm{BET}}\right)$ for ozone $(50 \mathrm{ppb}$, $25 \% \mathrm{RH}$ ) under dark (blue circles) and light (orange triangles) conditions at the surface of (a) five commercial brake pads and (b) six major brake pad components. Experiments were conducted in triplicate (brake pads) or duplicate (brake pad components), with each dark/light pair representing an individual experiment; error bars represent the experimental error, which we calculated as described in the ESI. $\uparrow$ In one case, the reactivity of the $\mathrm{Cu}-\mathrm{SiO}_{2}$ mixture was indistinguishable from the $\mathrm{SiO}_{2}$-only trials; data from this trial are not shown here (see ESI $\dagger$ ). All data shown here are also presented numerically in Table S8. $\dagger$

One reasonable approach to estimating the reactivity of compositionally complex PM is to represent it as the massnormalized sum of the reactivities of its constituents. Here, this approach only accounts for $15-35 \%$ of brake pad $\gamma_{\text {BET,SS }}$ values. We suggest four possible explanations for this "missing" reactivity. First, although we included reactivity contributions from all major components identified for our brake pad sample set, their overall reactivity may also reflect contributions from minor components identified by XRD (Table S5†). Second, as phenolic resin composition can differ between manufacturers ${ }^{21}$ and the reactivity of individual iron oxide phases can differ from sample to sample because of defects and/or different crystal structure parameters, ${ }^{35}$ it is also possible that the reactivities of the components we purchased and used in this study may differ from those of the corresponding components in actual brake pads. Third, direct comparison of the component and brake pad $\gamma_{\text {BET }}$ values is complicated by two factors: first, the components, when present in brake pads, likely exist as particles with specific surface areas different from those of the individual components studied here; second, the entirety of the component surface area may not be exposed/available for reaction with ozone when present as part of the overall brake pad mixture. Finally, we cannot exclude potential interactions between the different components, which could lead to differences between the total component reactivity as determined for the (internally mixed) brake pad and as determined by summing the reactivity of individual components.

\subsection{Time-dependent ozone uptake by brake materials}

Since brake wear is emitted directly into a mixture of preexisting pollutants, its immediate influence on urban ozone mixing ratios (e.g., during a given rush-hour period) is best captured using its initial uptake coefficient. As diffusion limitations (see ESI $\dagger$ ) prevent us from accurately determining this value for our samples, we instead report $\gamma_{\mathrm{BET}}$ as a function of ozone exposure time $(15,30$, and $60 \mathrm{~min})$; as sample illumination began only after $150 \mathrm{~min}$, at which point the ozone mixing ratios had reached a steady-state value, we present this analysis only for dark conditions.

As shown in Fig. $4 \mathrm{a}, \gamma_{\text {Вет }}$ values for all brake pads are higher at shorter ozone exposure times; assuming that the timedependent reactivity profile of emitted brake wear PM qualitatively resembles that of the parent brake material studied here, these results suggest that freshly emitted brake wear will be a more reactive surface for ozone uptake than atmospherically aged brake wear. Time-dependent ozone uptake has been observed for many atmospheric PM types, and has been attributed to saturation of reactive surface sites. ${ }^{23,25,26,36,37}$ Unlike $\gamma_{\text {BET,Ss, }}$, which are similar for all brake pads, $\gamma_{\mathrm{BET}, t}$ shows large sample-to-sample variation, with the ceramic and organic PBR samples having notably larger ratios of $\gamma_{\mathrm{BET}, 30 \mathrm{~min}}$ to $\gamma_{\mathrm{BET}, \mathrm{SS}}(29 \times$ and $15 \times)$ than the other samples $(5-8 \times$; see Table S11 $\uparrow$ for all ratios). As shown in Fig. $4 \mathrm{~b}$, the brake pad components also display different time dependencies, with the reactivity of some remaining small and relatively constant over time (Fe oxides) and others decreasing over time (phenolic resin, graphite, Fe, and $\mathrm{Cu}$ ). The strong time dependency calculated for the $\mathrm{Cu}$ powder $\left(\gamma_{\mathrm{BET}, 15 \mathrm{~min}} 17 \times\right.$ larger than $\left.\gamma_{\mathrm{BET}, \mathrm{SS}}\right)$ may explain in part the large time dependence of the ceramic and organic PBR samples, as they contain $5-13 \times$ more $\mathrm{Cu}$ than the other samples.

\subsection{Atmospheric significance}

The $\gamma_{\mathrm{BET}}$ values for ozone by brake pads that we report are at the upper end of those determined for atmospheric PM components; ${ }^{23-26,36,37}$ in addition, because the BET approach employed here may overestimate the accessible surface area of the particles when present as coatings in the flow tube, ${ }^{37}$ these $\gamma_{\text {BET }}$ values likely underestimate the ambient reactivity of this PM class. In the following paragraphs, we note additional experimental choices that may result in differences between the $\gamma_{\text {BET }}$ values reported here and the reactivity of "real-world" brake wear.

As discussed in the Section 2.2, we used ground brake pads as model particles of brake friction material. However, "real- 

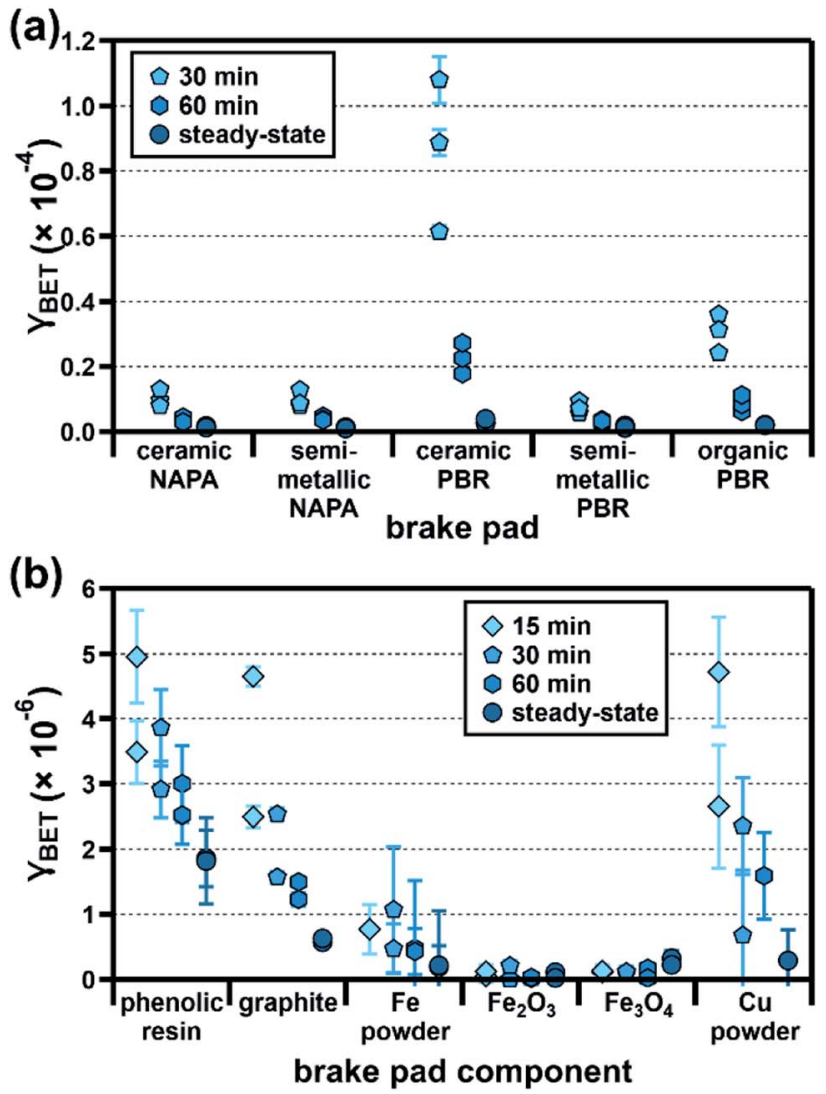

Fig. 4 Time-dependent BET uptake coefficients $\left(\gamma_{\mathrm{BET}}\right)$ for ozone $(50$ $\mathrm{ppb}, 25 \% \mathrm{RH}$ ) at the surface of (a) five commercial brake pads (30 and 60 min; steady-state) and (b) six major brake pad components (15, 30, and $60 \mathrm{~min}$; steady-state). Experiments were conducted in triplicate (brake pads) or duplicate (brake pad components), with each point at a given exposure time representing an individual experiment; error bars represent the experimental error, which we calculated as described in the ESI.† Due to high diffusion correction factors (see $E S \mid \dagger)$, the 15 min uptake coefficients for the brake pads are not shown. In some cases, the reactivity of the sample- $\mathrm{SiO}_{2}$ mixture was indistinguishable from the $\mathrm{SiO}_{2}$-only trials; data from these trials are not shown here (see ESI $\dagger$ ). All data shown here are also presented numerically in Table S9.†

world" brake wear (i.e., particles generated by the wear of actual automobile brakes) is formed through multiple simultaneous and complex processes, including abrasion of friction interfaces (i.e., between the brake pad and brake disc); mechanochemical reactions occurring due to the shear force, pressure, and heat generated during braking; and the evaporation and subsequent condensation of volatile species. ${ }^{9}$ Consequently, the composition of brake wear PM can differ from the parent brake material: for example, the organic components may degrade, and the iron may become oxidized. ${ }^{38}$ Based on our results, however, the effects of these changes on overall reactivity are inconclusive. For example, the degradation of organic resins may lead to a decrease in reactivity (Fig. 3b), whereas the oxidation of iron may or may not affect reactivity, as all forms of iron we tested (Fe powder, $\mathrm{Fe}_{2} \mathrm{O}_{3}$, and $\mathrm{Fe}_{3} \mathrm{O}_{4}$ ) had similar reactivity (Fig. 3b). Additionally, "real-world" brake wear also includes iron and iron oxide particles from the brake disc (typically cast-iron), ${ }^{\mathbf{1 6}}$ which, based on our results (Fig. 3b), may contribute to the overall reactivity of this PM class.

The five brake pad samples employed in this study were selected to enable us to compare the reactivity of multiple commercial classifications from the same manufacturer for the same car model; as noted in Table S1, $\dagger$ our sample set is representative of brake pads used in the older segment of the current vehicle fleet. ${ }^{39,40}$ Brake pad formulations have evolved over the years, often as a result of newly identified health concerns; for example, $\mathrm{Sb}_{2} \mathrm{~S}_{3}, \mathrm{Cu}, \mathrm{Pb}$, and asbestos have all been at least partially phased out by manufacturers. ${ }^{\mathbf{9 4 1}}$ One compositional change that may have a significant impact on overall brake pad atmospheric reactivity involves $\mathrm{Cu}$, which is currently being phased out in response to recent studies demonstrating that $\mathrm{Cu}$ contributes to brake pad toxicity. ${ }^{\mathbf{4 1 , 4 2}}$ Based on our component reactivity results (Fig. $3 \mathrm{~b}$ and $4 \mathrm{~b}$ ), which showed $\mathrm{Cu}$ to be an important contributor to both time-dependent (dark) and illuminated brake pad $\gamma_{\text {BET }}$ values, this development could result in a future decrease in brake pad reactivity.

Despite the high brake pad reactivities found in this study, the atmospheric importance of this ozone loss pathway is limited by the low absolute concentrations of brake wear PM; in particular, using typical $\mathrm{PM}_{2.5}$ brake wear loadings $(1.5 \mu \mathrm{g}$ $\left.\mathrm{m}^{-3}\right)^{\mathbf{4 3 , 4 4}}$ and $\gamma_{\mathrm{BET}, 30 \mathrm{~min}}, \gamma_{\mathrm{BET}, 60 \mathrm{~min}}$, or $\gamma_{\mathrm{BET}, \mathrm{SS}}$ values for our brake pads, and assuming that the reactivity of brake wear PM can be approximated by that of the parent brake material, we find that ozone loss to brake wear is always $<1 \%$ of its loss to the ground (detailed calculations are presented in the $\operatorname{ESI} \dagger$ ). Barring a situation in which ozone reactivity with brake wear PM is orders of magnitude larger than its reactivity with parent brake material, we conclude that brake wear chemistry alone will have minimal impact on urban ozone mixing ratios.

As near-road PM is compositionally complex, ${ }^{43}$ its interactions with gas-phase pollutants likely reflect contributions from multiple reactive PM classes (e.g., unsaturated organics). ${ }^{25,26}$ Using estimated PM loadings from a study in Toronto, Canada, ${ }^{43}$ assigning $\gamma_{\text {BET }}$ values based on published reactivity data for organic $\mathrm{PM},{ }^{25}$ and using $\gamma_{\mathrm{BET}, 30 \mathrm{~min}}$ values obtained here for ceramic and organic PBR brake pads (and again assuming that parent brake material is a reasonable proxy for atmospheric brake wear PM), we conclude that freshly emitted brake wear has the potential to be a more important ozone sink than organic PM (detailed calculations are presented in the $\operatorname{ESI} \dagger$ ). Ozone uptake by organic PM has been shown to alter a wide variety of PM properties, including hygroscopicity, ${ }^{34,36}$ viscosity, ${ }^{45,46}$ and toxicity. ${ }^{47,48}$ As we show above that the overall effect of brake wear PM on urban ozone mixing ratios is most likely small, we suggest that future research in this area focus on the potential impacts of brake wear-ozone interactions on brake wear properties, which has received little attention to date. $^{20}$

\section{Conclusions}

The composition of urban PM is both complex and dynamic: ${ }^{4}$ on a daily and seasonal scale, it reflects changes in meteorology 
(e.g., temperature, $\mathrm{RH}$ ), traffic patterns, and/or industrial emissions; over longer timescales, it reflects changes in source sector regulations and societal behaviour. For example, as vehicle exhaust emissions decrease and volatile chemical products begin to dominate the urban volatile organic compound (VOC) profile, the composition of secondary PM will change accordingly; ${ }^{49}$ in addition, the shift to electric vehicles will be accompanied by a decrease in exhaust emissions, but an increase in non-exhaust emissions. ${ }^{8}$ Currently, brake wear can contribute over half of non-exhaust $\mathrm{PM} ;{ }^{9}$ with the implementation of regenerative brakes in electric vehicles, this amount may decrease, ${ }^{8}$ resulting in road dust and tire wear becoming the dominant non-exhaust PM classes. These other classes will contribute to overall non-exhaust PM reactivity: for example, we have shown that road dust also reacts with ozone; ${ }^{50}$ tire wear, which contains both inorganic and unsaturated organic components, ${ }^{\mathbf{5 1}}$ may be similarly reactive. Additionally, tire wear oxidation products were recently found to be highly toxic to salmon. ${ }^{52}$ Therefore, to capture the full air quality impacts of non-exhaust PM, we need to understand the consequences of its interactions with other pollutants; this study is an important first step in this direction.

\section{Author contributions}

L. C. M. designed and conducted the flow tube experiments with assistance from K. A. R. S. and guidance from M. A.-G. and S. A. S.; D. T. M. performed BET analysis. L. C. M. and S. A. S. interpreted experimental data and wrote the manuscript with critical comments from M. A.-G. and D. T. M.

\section{Conflicts of interest}

There are no conflicts of interest to declare.

\section{Acknowledgements}

This research was undertaken, in part, thanks to funding from the Canada Research Chairs program. The authors thank Guangcheng Chen (previously at Canadian Centre for Isotopic Microanalysis, University of Alberta (U of A)) for ICP-MS analysis, Allan Harms (Natural Resources Analytical Laboratory, Department of Renewable Resources, U of A) for total carbon and nitrogen analysis, Jennifer Jones and Wayne Moffat (Analytical and Instrumentation Laboratory, Department of Chemistry, U of A) for TGA analysis and for helpful discussions, Dr Maureen Fitzpatrick and Dr James Britten (McMaster Analytical X-Ray Diffraction Facility, McMaster University) for XRD analysis, Dr Michael Katz (Department of Chemistry, Memorial University of Newfoundland) for access to gas adsorption infrastructure funded by the Natural Sciences and Engineering Research Council of Canada Research Tools and Instruments (NSERC RTI) grant program and the province of Newfoundland and Labrador, and Bakelite Synthetics for provision of the cured phenolic resin sample. The authors acknowledge the Department of Chemistry and the Faculty of Science at U of A as well as the Faculty of Science at McMaster
University for start-up funding, the Canada Foundation for Innovation (CFI) for funding through the John R. Evans Leaders Fund, the Alberta Ministry of Economic Development and Trade for funding through the Small Equipment Grants stream of the Research Capacity Program, and NSERC for funding through the Discovery Grant Program. L. C. M. acknowledges NSERC for support through the Canada Graduate Scholarship-Master's (CGS-M) and Canada Graduate Scholarship-Doctoral (CGS-D) programs.

\section{References}

1 A. J. Cohen, M. Brauer, R. Burnett, H. R. Anderson, J. Frostad, K. Estep, K. Balakrishnan, B. Brunekreef, L. Dandona, R. Dandona, V. Feigin, G. Freedman, B. Hubbell, A. Jobling, H. Kan, L. Knibbs, Y. Liu, R. Martin, L. Morawska, C. A. Pope III, H. Shin, K. Straif, G. Shaddick, M. Thomas, R. van Dingenen, A. van Donkelaar, T. Vos, C. J. L. Murray and M. H. Forouzanfar, Estimates and 25year trends of the global burden of disease attributable to ambient air pollution: an analysis of data from the Global Burden of Diseases Study 2015, Lancet, 2017, 389, 1907-1918.

2 F. Karagulian, C. A. Belis, C. F. C. Dora, A. M. Prüss-Ustün, S. Bonjour, H. Adair-Rohani and M. Amann, Contributions to cities' ambient particulate matter (PM): A systematic review of local source contributions at global level, Atmos. Environ., 2015, 120, 475-483.

$3 \mathrm{M}$. Rexeis and S. Hausberger, Trend of vehicle emission levels until 2020 - Prognosis based on current vehicle measurements and future emission legislation, Atmos. Environ., 2009, 43, 4689-4698.

4 C.-H. Jeong, A. Traub, A. Huang, N. Hilker, J. M. Wang, D. Herod, E. Dabek-Zlotorzynska, V. Celo and G. J. Evans, Long-term analysis of $\mathrm{PM}_{2.5}$ from 2004 to 2017 in Toronto: Composition, sources, and oxidative potential, Environ. Pollut., 2020, 263, 114652.

5 European Environment Agency (EEA), European Union emission inventory report 1990-2018: under the UNECE convention on long-range transboundary air pollution (LRTAP), https:/www.eea.europa.eu//publications/ european-union-emission-inventory-report-1990-2018, accessed 22 January 2021.

6 J. Zhang, J. Peng, C. Song, C. Ma, Z. Men, J. Wu, L. Wu, T. Wang, X. Zhang, S. Tao, S. Gao, P. K. Hopke and H. Mao, Vehicular non-exhaust particulate emissions in Chinese megacities: Source profiles, real-world emission factors, and inventories, Environ. Pollut., 2020, 266, 115268.

7 V. Singh, A. Biswal, A. P. Kesarkar, S. Mor and K. Ravindra, High resolution vehicular $\mathrm{PM}_{10}$ emissions over megacity Delhi: Relative contributions of exhaust and non-exhaust sources, Sci. Total Environ., 2020, 699, 134273.

8 D. C. S. Beddows and R. M. Harrison, $\mathbf{P M}_{10}$ and $\mathbf{P M}_{2.5}$ emission factors for non-exhaust particles from road vehicles: Dependence upon vehicle mass and implications for battery electric vehicles, Atmos. Environ., 2021, 244, 117886. 
9 T. Grigoratos and G. Martini, Brake wear particle emissions: a review, Environ. Sci. Pollut. Res., 2015, 22, 2491-2504.

10 P. G. Sanders, N. Xu, T. M. Dalka and M. M. Maricq, Airborne brake wear debris: Size distributions, composition, and a comparison of dynamometer and vehicle tests, Environ. Sci. Technol., 2003, 37, 4060-4069.

11 B. D. Garg, S. H. Cadle, P. A. Mulawa, P. J. Groblicki, C. Laroo and G. A. Parr, Brake wear particulate matter emissions, Environ. Sci. Technol., 2000, 34, 4463-4469.

12 A. Iijima, K. Sato, K. Yano, M. Kato, K. Kozawa and N. Furuta, Emission factor for antimony in brake abrasion dusts as one of the major atmospheric antimony sources, Environ. Sci. Technol., 2008, 42, 2937-2942.

13 J. Kukutschová, P. Moravec, V. Tomášek, V. Matějka, J. Smolík, J. Schwarz, J. Seidlerová, K. Šafářová and P. Filip, On airborne nano/micro-sized wear particles released from low-metallic automotive brakes, Environ. Pollut., 2011, 159, 998-1006.

14 M. Alemani, O. Nosko, I. Metinoz and U. Olofsson, A study on emission of airborne wear particles from car brake friction pairs, SAE Int. J. Mater. Manuf., 2016, 9, 147-157.

15 O. Nosko and U. Olofsson, Quantification of ultrafine airborne particulate matter generated by the wear of car brake materials, Wear, 2017, 374-375, 92-96.

16 J. H. J. Hulskotte, G. D. Roskam and H. A. C. Denier van der Gon, Elemental composition of current automotive braking materials and derived air emission factors, Atmos. Environ., 2014, 99, 436-445.

17 M. Gasser, M. Riediker, L. Mueller, A. Perrenoud, F. Blank, P. Gehr and B. Rothen-Rutishauser, Toxic effects of brake wear particles on epithelial lung cells in vitro, Part. Fibre Toxicol., 2009, 6, 30.

18 M. E. Gerlofs-Nijland, B. G. H. Bokkers, H. Sachse, J. J. E. Reijnders, M. Gustafsson, A. J. F. Boere, P. F. H. Fokkens, D. L. A. C. Leseman, K. Augsburg and F. R. Cassee, Inhalation toxicity profiles of particulate matter: a comparison between brake wear with other sources of emission, Inhal. Toxicol., 2019, 31, 89-98.

19 L. Selley, L. Schuster, H. Marbach, T. Forsthuber, B. Forbes, T. W. Gant, T. Sandström, N. Camiña, T. J. Athersuch, I. Mudway and A. Kumar, Brake dust exposure exacerbates inflammation and transiently compromises phagocytosis in macrophages, Metallomics, 2020, 12, 371-386.

20 J. Zhao, N. Lewinski and M. Riediker, Physico-chemical characterization and oxidative reactivity evaluation of aged brake wear particles, Aerosol Sci. Technol., 2015, 49, 65-74.

21 D. Chan and G. W. Stachowiak, Review of automotive brake friction materials, Proc. Inst. Mech. Eng., Part D, 2004, 218, 953-966.

22 C. E. Kolb, R. A. Cox, J. P. D. Abbatt, M. Ammann, E. J. Davis, D. J. Donaldson, B. C. Garrett, C. George, P. T. Griffiths, D. R. Hanson, M. Kulmala, G. McFiggans, U. Pöschl, I. Riipinen, M. J. Rossi, Y. Rudich, P. E. Wagner, P. M. Winkler, D. R. Worsnop and C. D. O' Dowd, An overview of current issues in the uptake of atmospheric trace gases by aerosols and clouds, Atmos. Chem. Phys, 2010, 10, 10561-10605.
23 M. Abou-Ghanem, A. O. Oliynyk, Z. Chen, L. C. Matchett, D. T. McGrath, M. J. Katz, A. J. Locock and S. A. Styler, Significant variability in the photocatalytic activity of natural titanium-containing minerals: Implications for understanding and predicting atmospheric mineral dust photochemistry, Environ. Sci. Technol., 2020, 54, 1350913516.

24 P. K. Mogili, P. D. Kleiber, M. A. Young and V. H. Grassian, Heterogeneous uptake of ozone on reactive components of mineral dust aerosol: An environmental aerosol reaction chamber study, J. Phys. Chem. A, 2006, 110, 13799-13807.

25 B. D'Anna, A. Jammoul, C. George, K. Stemmler, S. Fahrni, M. Ammann and A. Wisthaler, Light-induced ozone depletion by humic acid films and submicron aerosol particles, J. Geophys. Res., 2009, 114, D12301.

26 S. A. Styler, M. Brigante, B. D'Anna, C. George and D. J. Donaldson, Photoenhanced ozone loss on solid pyrene films, Phys. Chem. Chem. Phys., 2009, 11, 7876-7884.

27 C. George, B. D'Anna, H. Herrmann, C. Weller, V. Vaida, D. J. Donaldson, T. Bartels-Rausch and M. Ammann, in Atmospheric and Aerosol Chemistry, ed. V. F. McNeill and P. A. Ariya, Springer, Berlin, Heidelberg, 2012, vol. 339, pp. 154.

28 D. S. T. Hjortenkrans, B. G. Bergbäck and A. V. Häggerud, Metal emissions from brake linings and tires: Case studies of Stockholm, Sweden 1995/1998 and 2005, Environ. Sci. Technol., 2007, 41, 5224-5230.

29 Canadian Council of Ministers of the Environment, 2017 Canada Air Quality Report, https://www.ccme.ca/en/airquality-report, accessed 29 January 2021.

30 S. D. Razumovskii, V. N. Gorshenev, A. L. Kovarskii, A. M. Kuznetsov and A. N. Shchegolikhin, Carbon nanostructure reactivity: Reactions of graphite powders with ozone, Fullerenes, Nanotubes, Carbon Nanostruct., 2007, 15, 53-63.

31 E. Humeres, K. M. de Castro, N. A. Debacher and R. d. F. P. M. Moreira, Reaction mechanism of the reduction of ozone on graphite, Langmuir, 2020, 36, 1122511236.

$32 \mathrm{~S}$. Oesch, The effect of $\mathrm{SO}_{2}, \mathrm{NO}_{2}$, $\mathrm{NO}$ and $\mathrm{O}_{3}$ on the corrosion of unalloyed carbon steel and weathering steel - The results of laboratory exposures, Corros. Sci., 1996, 38, 1357-1368.

$33 \mathrm{~S}$. Oesch and $\mathrm{M}$. Faller, Environmental effects on materials: The effect of the air pollutants $\mathrm{SO}_{2}, \mathrm{NO}_{2}, \mathrm{NO}$ and $\mathrm{O}_{3}$ on the corrosion of copper, zinc and aluminium. A short literature survey and results of laboratory exposures, Corros. Sci., 1997, 39, 1505-1530.

34 A. Jammoul, S. Gligorovski, C. George and B. D'Anna, Photosensitized heterogeneous chemistry of ozone on organic films, J. Phys. Chem. A, 2008, 112, 1268-1276.

35 Y. AlSalka, L. I. Granone, W. Ramadan, A. Hakki, R. Dillert and D. W. Bahnemann, Iron-based photocatalytic and photoelectrocatalytic nano-structures: Facts, perspectives, and expectations, Appl. Catal., B, 2019, 244, 1065-1095.

36 V. Zelenay, M. E. Monge, B. D'Anna, C. George, S. A. Styler, T. Huthwelker and M. Ammann, Increased steady state 
uptake of ozone on soot due to UV/Vis radiation, J. Geophys. Res., 2011, 116, D11301.

37 Z. L. Coates Fuentes, T. M. Kucinski and R. Z. Hinrichs, Ozone decomposition on kaolinite as a function of monoterpene exposure and relative humidity, ACS Earth Space Chem., 2018, 2, 21-30.

38 J. Kukutschová, V. Roubíček, M. Mašláň, D. Jančík, V. Slovák, K. Malachová, Z. Pavlíčková and P. Filip, Wear performance and wear debris of semimetallic automotive brake materials, Wear, 2010, 268, 86-93.

39 United States Department of Transportation, Average Age of Automobiles and Trucks in Operation in the United States, https://www.bts.gov/content/average-age-automobiles-andtrucks-operation-united-states, accessed 3 September 2021.

40 European Automobile Manufacturers' Association (ACEA), Average age of the EU vehicle fleet, by country, https:// www.acea.auto/figure/average-age-of-eu-vehicle-fleet-bycountry/, accessed 3 September 2021.

41 Y. Lyu, M. Leonardi, J. Wahlström, S. Gialanella and U. Olofsson, Friction, wear and airborne particle emission from Cu-free brake materials, Tribol. Int., 2020, 141, 105959.

42 M. Figliuzzi, M. Tironi, L. Longaretti, A. Mancini, F. Teoldi, F. Sangalli and A. Remuzzi, Copper-dependent biological effects of particulate matter produced by brake systems on lung alveolar cells, Arch. Toxicol., 2020, 94, 2965-2979.

43 C.-H. Jeong, J. M. Wang, N. Hilker, J. Debosz, U. Sofowote, Y. Su, M. Noble, R. M. Healy, T. Munoz, E. DabekZlotorzynska, V. Celo, L. White, C. Audette, D. Herod and G. J. Evans, Temporal and spatial variability of trafficrelated $\mathrm{PM}_{2.5}$ sources: Comparison of exhaust and nonexhaust emissions, Atmos. Environ., 2019, 198, 55-69.

44 F. Amato, M. Pandolfi, A. Escrig, X. Querol, A. Alastuey, J. Pey, N. Perez and P. K. Hopke, Quantifying road dust resuspension in urban environment by Multilinear Engine: A comparison with PMF2, Atmos. Environ., 2009, 43, 27702780 .

45 A. Athanasiadis, C. Fitzgerald, N. M. Davidson, C. Giorio, S. W. Botchway, A. D. Ward, M. Kalberer, F. D. Pope and M. K. Kuimova, Dynamic viscosity mapping of the oxidation of squalene aerosol particles, Phys. Chem. Chem. Phys., 2016, 18, 30385-30393.

46 Y. Chu and C. K. Chan, Role of oleic acid coating in the heterogeneous uptake of dimethylamine by ammonium sulfate particles, Aerosol Sci. Technol., 2017, 51, 988-997.

47 E. Z. Nordin, O. Uski, R. Nyström, P. Jalava, A. C. Eriksson, J. Genberg, P. Roldin, C. Bergvall, R. Westerholm, J. Jokiniemi, J. H. Pagels, C. Boman and M.-R. Hirvonen, Influence of ozone initiated processing on the toxicity of aerosol particles from small scale wood combustion, Atmos. Environ., 2015, 102, 282-289.

48 J. Zhu, Y. Chen, J. Shang and T. Zhu, Effects of air/fuel ratio and ozone aging on physicochemical properties and oxidative potential of soot particles, Chemosphere, 2019, 220, 883-891.

49 B. C. McDonald, J. A. de Gouw, J. B. Gilman, S. H. Jathar, A. Akherati, C. D. Cappa, J. L. Jimenez, J. Lee-Taylor, P. L. Hayes, S. A. McKeen, Y. Y. Cui, S.-W. Kim, D. R. Gentner, G. Isaacman-VanWertz, A. H. Goldstein, R. A. Harley, G. J. Frost, J. M. Roberts, T. B. Ryerson and M. Trainer, Volatile chemical products emerging as largest petrochemical source of urban organic emissions, Science, 2018, 359, 760-764.

50 M. Abou-Ghanem, D. Nodeh-Farahani, D. T. McGrath, M. J. Katz, T. C. VandenBoer and S. A. Styler, Ozone uptake and halogen activation by road dust and anti-icing solution: Implications for wintertime urban air quality, unpublished work.

51 A. Thorpe and R. M. Harrison, Sources and properties of non-exhaust particulate matter from road traffic: A review, Sci. Total Environ., 2008, 400, 270-282.

52 Z. Tian, H. Zhao, K. T. Peter, M. Gonzalez, J. Wetzel, C. Wu, X. Hu, J. Prat, E. Mudrock, R. Hettinger, A. E. Cortina, R. G. Biswas, F. V. C. Kock, R. Soong, A. Jenne, B. Du, F. Hou, H. He, R. Lundeen, A. Gilbreath, R. Sutton, N. L. Scholz, J. W. Davis, M. C. Dodd, A. Simpson, J. K. McIntyre and E. P. Kolodziej, A ubiquitous tire rubber-derived chemical induces acute mortality in coho salmon, Science, 2021, 371, 185-189. 